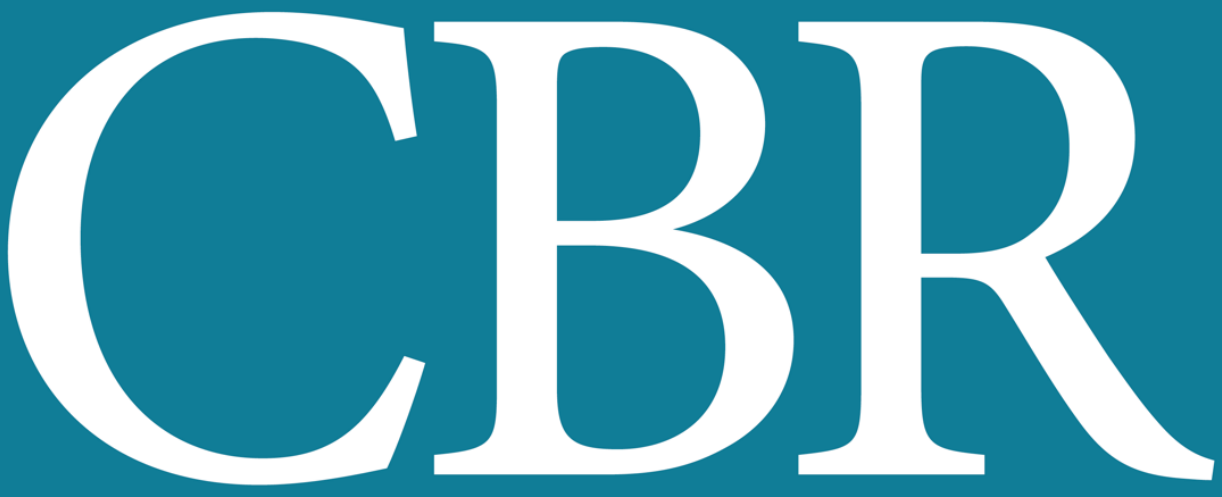

INTERNATIONAL JOURNAL OF CANCER AND BIOMEDICAL RESEARCH

https://jcbr.journals.ekb.eg

Editor-in-chief

Prof. Mohamed Labib Salem, PhD

Expression of Adenosine Receptors in Young Patients with Breast Cancer and its Association with High Proliferative Index

Maha Guimei and Mohamed A. Eladl 


\section{Welcome letter from Editor-in-Chief}

Welcome to the Int J Cancer and Biomedical Research (IJCBR)!

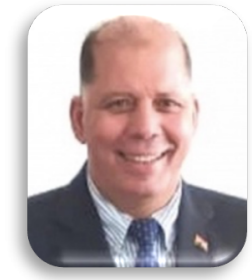

It is with great pleasure that I write this editorial to welcome you to the IJCBR. This journal provides a platform for publication of original and reviews research articles, short communications, letter to editor, thesis abstract, conference report, and case studies. These types of publication are directed at the interface of the fields of cancer and biomedical research.

The IJCBR relies on a distinguished expert of the Advisory and Editorial Board Members from the top international league covering in depth the related topics. They timely review all manuscripts and maintain highest standards of quality and scientific methodology and ethical concepts. Meanwhile, we take all possible means to keep the time of the publication process as short as possible.

I take this chance to welcome your contributions to the IJCBR and have every expectation that it will soon become one of the most respected journals in both the fields of cancer and biomedical research.

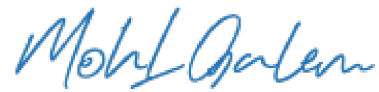

Mohamed L. Salem,

Editor in Chief 


\title{
Expression of Adenosine Receptors in Young Patients with Breast Cancer and its Association with High Proliferative Index
}

\author{
Maha Guimei ${ }^{1}$ and Mohamed A. Eladl ${ }^{2}$ \\ ${ }^{1}$ Pathology Department, Alexandria University, Alexandria, Egypt \\ ${ }^{2}$ Basic Medical Sciences, University of Sharjah, Sharjah, United Arab Emirates
}

\section{ABSTRACT}

\section{ARTICLE INFO}

Background: Adenosine is produced in the hypoxic tumor milieu. By stimulating its receptors, it plays an important role not only in evading the body's immune mechanisms but also in enhancing tumor vasculature and contributing to tumor aggressiveness. Aim: The present study aimed at investigating the immunohistochemical expression of Adenosine receptors (A2A) in breast cancer tissue and its association with different clinico-pathological parameters. Materials and Methods: Thirty formalin-fixed paraffin-embedded (FFPE) breast cancer specimens were immunohistochemically stained using A2AR antibodies. All clinical and pathological data were retrospectively retrieved from the patients' records. Results: Cytoplasmic expression of A2ARs was noted not only on the tumor immune cells but also on the tumor cells themselves. They were strongly expressed on the tumor cells in $73.3 \%$ ( $n=22$ ) of tumors. Expression was significantly higher in younger aged patients ( $<50$ years old) compared to older ones [ $p=0.044]$. A2AR expression was also significantly higher in Luminal $B$ and triple negative compared to Luminal $A$ tumors $[\mathrm{p}=0.028]$. The majority of A2AR expressing tumors had a mitotic index score of $2[p=0.013]$ as well as a significantly higher proliferative index (ki-67 $>20 \%$ ) $[p=0.018]$. No association was observed between A2AR expression and tumor size, type, grade, Lymph node status, percentage of TILs or patient survival after 2 years of follow-up. Conclusion: These findings suggest a possible role for Adenosine in imparting a more aggressive phenotype in breast cancer and that targeting these receptors using Adenosine receptor antagonists could have a potential role in improving the outcome of these patients.

Keywords: Adenosine Receptors; Adenosine Receptors antagonists, luminal B, Triple negative, breast cancer.

Editor-in-Chief: Prof. M.L. Salem, PhD - Article DOI: 10.21608/jcbr.2020.44152.1073

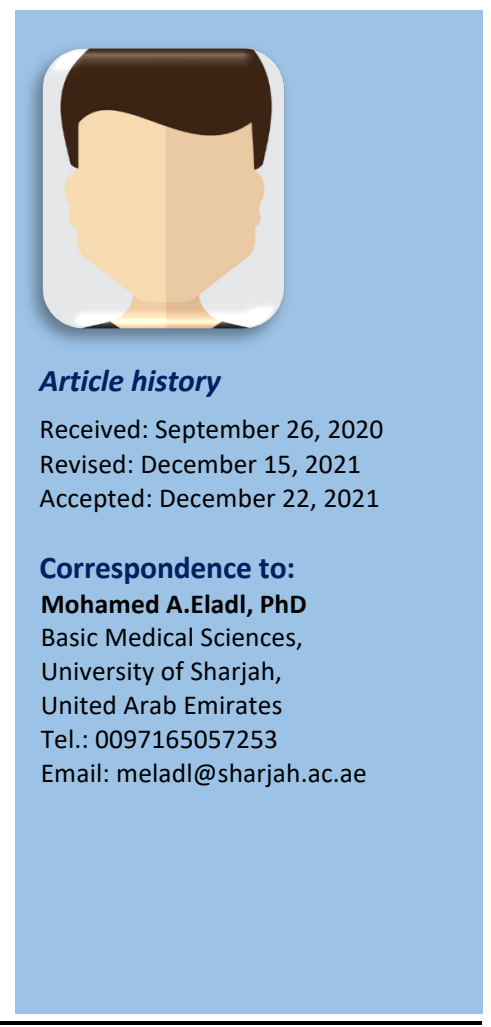

\section{INTRODUCTION}

Despite the great advances in Breast Cancer screening, early diagnosis, and treatment, it remains the most common cancer in females and the second most common cancer killer after lung cancer, with many cases still encountering therapeutic failures (Tarver, 2012). Therefore, the search for new prognostic and therapeutic molecules is still ongoing aiming to further improve the outcome and reduce the number of recurrences and metastasis in breast cancer patients.

In the past decade, there has been a considerable focus on the understanding of the complex interplay between the tumor cells and their surrounding microenvironment. Evasion of the anti-tumor immune response has emerged as one of the hallmarks of cancer as well as a key contributor to tumor progression and a widely sought-after therapeutic target. Numerous molecules are now recognized as targets for immunotherapy, also described as "immune checkpoints" (Allard et al., 2016; Inoue et al., 2017).

Currently, the clinical application of immune checkpoint targeting drugs has yielded great success in the treatment of many tumors. Antibodies against Programmed-death-ligand1 (PD-L1) and cytotoxic-T lymphocyte antigen-4 (CTLA-4) are currently FDA-approved drugs that are being successfully used for the treatment of 
advanced malignant melanomas (Johnson et al., 2015). Amongst a newer generation of immunooncology drugs, those targeting adenosinemediated immunosuppression via CD73 and Adenosine receptor (A2a) are currently being investigated (Allardet al., 2016; Antonioli et al., 2016).

Adenosine is an ancient signaling molecule that has a crucial role in regulating various cellular processes during cancer development. It is produced both intracellularly and extracellularly. Intracellular adenosine is produced from its immediate precursor, 5'adenosine monophosphate (5'-AMP), by the action of the enzyme 5'-nucleotidase. This adenosine is important for energy and nucleic acid metabolism and can later be transported extracellularly (Sheth et al., 2014). Adenosine generated in the extracellular space is formed by the breakdown of ATP through a series of ectoenzymes, including (CD39) and (CD73) present on the cell surface (Eltzschig, 2013; Longhi et al., 2013). Under normal physiologic conditions, Adenosine generated in the extracellular space serves to protect the tissues against excessive inflammation and promotes repair mechanisms. Its level is relatively low and certainly below the sensitivity threshold of the various immune cells. However, during the hypoxic conditions, that normally characterize the tumor microenvironment (TME), Hypoxia Inducible Factor (HIF-1 $\alpha$ ) activates CD73 and CD39 and results in marked upregulation of extracellular Adenosine levels (Ohta, 2016). Hypoxia in the TME is, on one hand, the result of the increased oxygen demand of the proliferating tumor cells, and on the other hand, related to the inefficient blood supply offered by the tortuous tumor vasculature. In that harsh environment, Adenosine is usually present at high concentrations and is a crucial mediator of tumor cell growth as well as evasion of the antitumor immune response (Antonioli et al., 2013; Longhi et al., 2013; Ohta, 2016). Adenosine mediates its physiological functions through its interaction with four G-proteincoupled receptors A1, A2A, A2B, and A3 (Gessi et al., 2011). Although all adenosine receptors now have an increasing number of recognized biological roles in tumors, it seems that the $A 2 A R$ is the most expressed on immune cells and both $A 2 A$ and $A 3$ subtypes are the most promising regarding drug development (Fredholm et al., 2001; Leone \& Powell, 2015).

Activation of $A 2 A$ receptors results in an immunosuppressive effect and evasion of antitumor immune response via several mechanisms. Their activation on human or mouse $T$ cells was shown to decrease the secretion of various Th1/Th2 cytokines including, but not limited to, IL-2, IL-4, IL-5, IFN$\gamma$ and TNF- $\alpha$ (Allard et al., 2016). Moreover, A2AR activation resulted in a decreased T-cell proliferation as well as activation and induction of profound T cell apoptosis (Longhi et al., 2013). Furthermore, stimulation of A2AR on the surface of T-cells has also lead to downregulation of T-cell receptor expression (Hatfield \& Sitkovsky, 2016). A2A receptors also have an inhibitory effect on the cytotoxic activity of NK cells. Indeed, the activation of these receptors resulted in the inhibition of perforin-mediated and CD95 ligand-mediated lysis of tumor cells. Their effect also further extends to a suppressive effect on anti-tumor M1 macrophages with decreased MHCII and IL12 expression and increased IL-10 expression (Allard et al., 2016; Antonioli et al., 2013).

In addition to its effect on the anti-tumor immune response, Adenosine can also have a direct effect on tumor cell growth and proliferation. Stimulation of Adenosine receptors on the tumor cells inhibited tumor cell apoptosis, enhanced angiogenesis and promoted tumor metastatic potential (Antonioli et al., 2013; Ohta, 2016) . A number of studies have investigated the potential role of targeting Adenosine pathway in order to enhance the anti-tumor immune response. This was done either by targeting CD39 or CD73 to decrease Adenosine production in the tumor milieu or by Targeting A2A receptors to restore the antitumor function of the different immune cells in the TME (Beavis et al., 2015; Häusler et al., 2014).

A2A receptors antagonists have been developed and studied for the treatment of Parkinson's disease and they were found to be safe and well-tolerated in clinical trials. In recent years, they have also entered phase I 
clinical trials for oncology (NCT02403193 and NCT02655822) (Beavis et al., 2015).

To the best of our knowledge, the expression profiles and clinical significance of A2A receptors in human breast cancer tissue has not been fully investigated. Moreover, little information is available about the prognostic effect of tumor A2AR expression and its association with other clinicopathological parameters. In the present study, we evaluated A2AR expression in surgically resected breast cancer tissue. Associations between their expression and the different clinicopathological parameters, as well as patients' prognoses, were analyzed.

\section{MATERIALS AND METHODS Patients and specimen collection}

The present study was conducted on 30 formalin-fixed paraffin-embedded (FFPE) breast cancer tumor specimens from Egyptian patients who have been diagnosed using a US-guided biopsy followed by curative surgical treatment in Alexandria university hospitals, Egypt. Written informed consent to use these specimens for medical research was obtained from all patients. Clinical and pathological data were retrospectively retrieved by the review of the patients' records.

Two independent pathologists reviewed the tumor specimens to confirm the tumor type, Nottingham grade, TNM stage, mitotic count, lymphovascular invasion, and presence or absence of in situ tumor component. The percentage of tumor-infiltrating lymphocytes (TILS) was also assessed in the H\&E stained sections by 2 independent pathologists blinded from the clinical information and an average percentage was agreed upon based on the criteria proposed by the International TILS Working group (Salgado et al., 2014). Data concerning both the hormone receptor status (ER, PR) and the HER2 expression for each tumor were retrieved from the patients' records. Patients' followed up data (tumor recurrence, metastasis as well as patient survival) after a period ranging between 2 and 5 years were also recorded.

\section{Immunohistochemistry procedures and interpretation}

Unstained slides of FFPE tumor tissue were used for the immunohistochemical staining. Representative samples were stained using A2AR primary mouse monoclonal antibody (dilution 1:100, clone SC-32261, Santa Cruz Biotechnology, USA), Ki67 monoclonal antibody (dilution 1:200, MIB1 clone, Dako, Denmark), as well as basal-like markers CK5 Rabbit monoclonal antibody (dilution 1:100, Abcam, ab52635) and CK6 mouse monoclonal antibody (dilution 1:100, Abcam, ab18586). Positive and negative controls were included in all the runs. All slides were deparaffinized in xylene then rehydrated in descending concentrations of alcohol. Heat-mediated antigen retrieval in citrate buffer was performed using a microwave before starting the immunohistochemical staining protocol. The streptavidin-biotinperoxidase complex method was used. This technique involves sequential incubation of the specimens with an unconjugated primary antibody specific to the target antigen, a biotylinated secondary antibody that reacts with the primary antibody, enzyme-labeled streptavidin, and DAB substrate chromogen. The Abcam Detection kits (Mouse specific HRP/DAB (ABC) detection IHC kit, ab64259) and (Rabbit specific HRP/DAB detection kit, ab64261) were used.

For A2AR staining, semi-quantitative (Modified $\mathrm{H}$-score) method was used to assess the degree of positive staining. This method assigns an IHC $\mathrm{H}$-score to each patient on a continuous scale of $0-300$, based on the percentage of positively stained cells at different staining intensities (Pirker et al., 2012). In this method, membranous and cytoplasmic staining of A2ARs was scored according to four categories: 0 for 'no staining', $1+$ for 'light staining visible only at high magnification', 2 + for 'intermediate staining' and $3+$ for 'dark staining, visible even at low magnification'. The percentage of cells at different staining intensities was determined by visual assessment, with the score calculated using the formula $1 \times$ (\% of $1+$ cells) $+2 \times$ (\% of $2+$ cells $)+3 \times(\%$ of $3+$ cells $)$ depending on the percentage of stained cells. Stromal lymphocytes that exhibited positive staining were used as an internal positive control. 
Ki-67 scoring was performed by both semiquantitative assessments (visual counting and image analysis). As for the semi-quantitative assessment of Ki-67; three fields each containing 100 malignant cells were evaluated at a time and an average was calculated. The number of brown-stained nuclei regardless of intensity is designated as a fraction out of the total number of malignant nuclei (Inwald et al., 2013). A Ki-67 cut-off point of $20 \%$ was defined according to previous recommendations (Bustreo et al., 2016). Image analysis for Ki-67 was carried out using ImmunoRatio ${ }^{\circledR}$ plugin which is part of ImageJ software. Two images per tumor were captured using Olympus microscope equipped with a color camera and submitted for analysis.

CK5/6 IHC was performed using CK5 rabbit monoclonal antibody (dilution 1:100, Abcam, ab52635) and CK6 mouse monoclonal antibody (dilution 1:100, Abcam, ab18586). Basal cell carcinoma was used as a positive control. Intermediate to strong cytoplasmic staining in more than $10 \%$ of the cells were considered positive, weak to intermediate staining in less than $10 \%$ of the cells was considered focally positive and no staining was considered negative.

\section{Statistical analysis}

Data were analyzed using the Statistical Package for Social Science (SPSS) program (version 21). Data were entered as numerical or categorical as appropriate. Data were described using minimum, maximum, mean, standard deviation and $95 \%$ confidence interval $(95 \% \mathrm{Cl})$ of the mean for the normally distributed. Categorical variables were described using frequency and percentage of the total. For non-normallydistributed data, comparisons between two studied independent groups were carried out using the Mann-Whitney $U$ test.

Comparisons were carried out between more than two independently studied not normallydistributed subgroups using Kruskal-Wallis test. Chi-square test was used to test the association between qualitative variables. Fischer's exact test and Monte Carlo correlation was carried out when indicated. An alpha level was set to $5 \%$ with a significance level of $95 \%$, and a beta error accepted up to $20 \%$ with a power of study of $80 \%$. Recurrence data were analyzed using the Kaplan-Meier estimator method. The logrank test was used for the comparison of recurrence curves. Statistical significance was set at $p<0.05$.

\section{RESULTS}

The present study comprised $30 \mathrm{BC}$ patients. Eighteen (60\%) of whom were less than 50 years of age and $12(40 \%)$ were 50 years of age and above. Histopathologic evaluation of the tumors revealed that $28 / 30$ (93.3\%) cases were invasive ductal carcinomas, no special type (IDC, NST) and two were classified as invasive lobular carcinoma (ILC). As for the hormone receptor expression, 19 cases (63.3\%) were ER-positive whereas 11 (36.7\%) were ER-negative. Twentyone patients (70\%) were HER2 negative and 9 (30\%) were HER2 positive by immunohistochemistry and FISH analysis.

Based on the review of the tumors' hormonal profiles from the patients' records and based on the interpretation of the immunohistochemical staining of $\mathrm{CK} 5, \mathrm{CK} 6$, and $\mathrm{Ki}-67$ proliferation index, Tumors were molecularly subclassified into Luminal A (10 cases), luminal B (13 cases), Her-2 enriched (1 case), Triple-negative (6 cases), and basal-like ( 0 case). The percentage of tumor-infiltrating lymphocytes in each tumor was evaluated and tumors were classified as mild (up to $5 \%$ ), moderate (5-9\%) and strong (more than 10\%) (Lee et al., 2015) (Figure 1).

Adenosine receptors (A2AR) were expressed not only on the tumor-associated immune cells (Figure 3) but also on the tumor cells themselves. A2AR were expressed in all examined tumor specimens but with varying staining intensities. Eight (8) out of 30 cases (26.7\%) showed weak A2A expression ( $\mathrm{H}$-score below 100) whereas the remaining 22 cases (73.3\%) showed moderate to strong expression A2AR expression ( $\mathrm{H}$-score between 100-300) (Figure $2 \mathrm{a}, \mathrm{b}, \mathrm{c}$ ). A2AR expression on the tumor cells was significantly higher in younger patients compared to older patients where $88.8 \%$ of the young patients $(<50 y s)$ showed strong expression of A2AR compared to only $50 \%$ of the older patients showing strong expression of A2AR ( $p=0.018$, Chi-square test). 

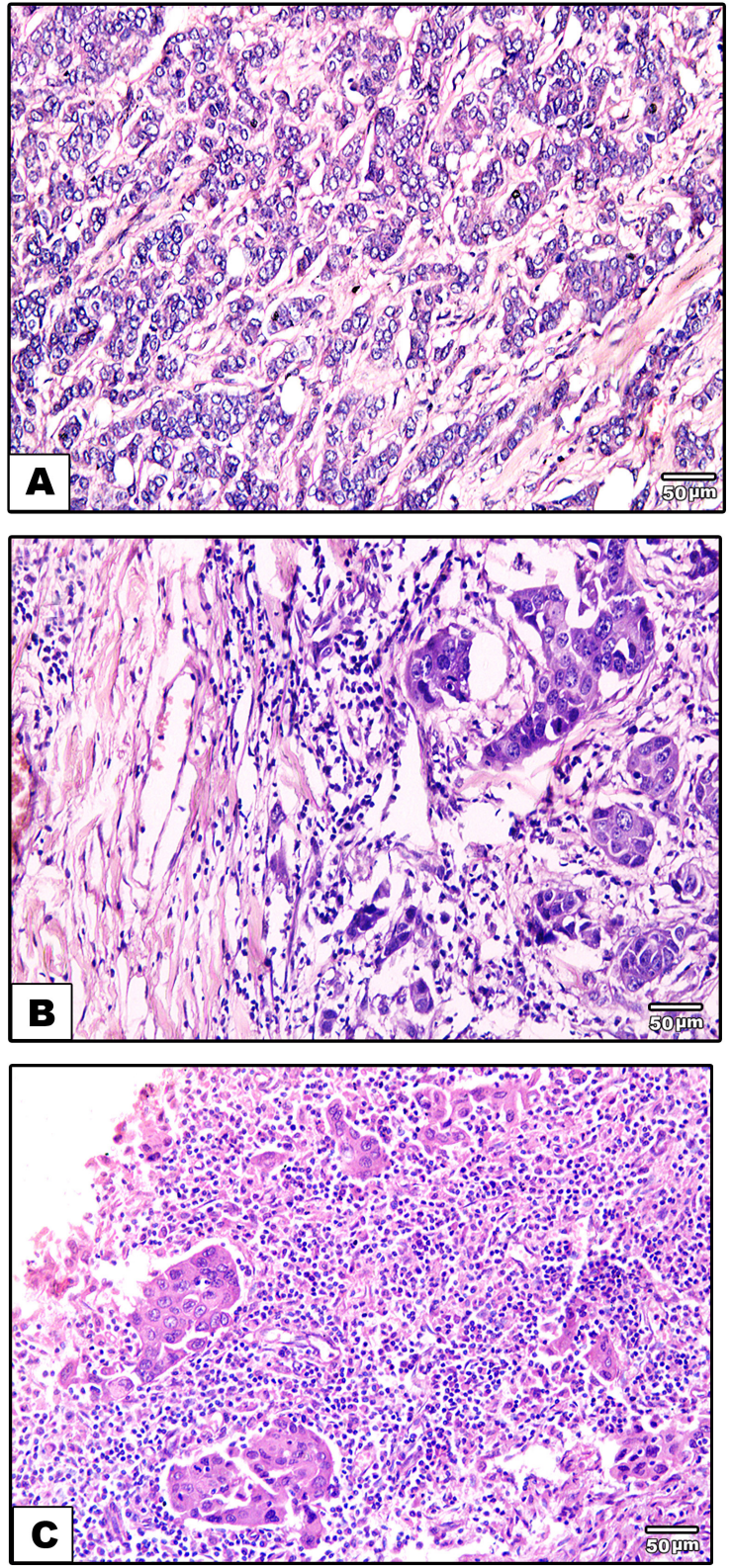

Figure 1. Microscopic picture of breast cancer tumors showing variable infiltration with tumor-infiltratinglymphocytes (TILs) in the studied tumor specimens. (A) No lymphocytes within the tumor tissue. (B) Moderate infiltration with TILs (9\%). (C) Marked infiltration with lymphocytes (80\%).

Tumors molecularly classified as "Luminal B", "triple-negative breast cancer (TNBC)" and "HER2 enriched" subtypes showed a higher A2AR expression compared to luminal A tumors $(p=0.028$, Pearson chi-square test). A significant association was also noted between A2AR expression and a high Mitotic score $(p=0.013$, Pearson chi-square test) as well as a high proliferative index (as evidenced by a high Ki-67 expression $>20 \%)(P=0.018$, Pearson's chisquare test).
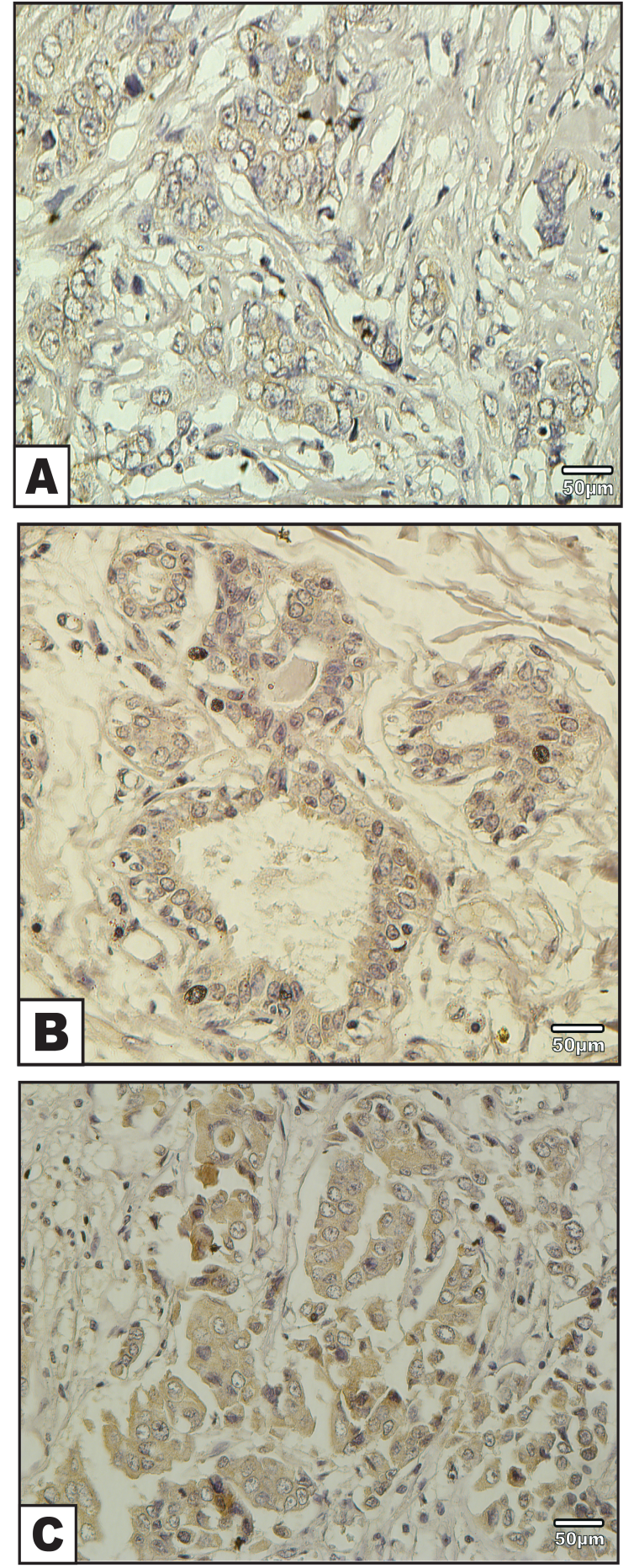

Figure 2. Microscopic evaluation of Immunohistochemical expression of A2ARs in the studied specimens. (A) Mild membranous expression of A2A receptors (H-score 60) on the surface of the tumor cells. Note that the intensity of staining is very mild and only noted on high magnification. (B) Moderate expression of A2A receptors. A welldifferentiated tumor formed of variable-sized tubules shows a moderate membranous expression of A2A receptors (H-score 180). (C) A moderately differentiated tumor formed of nests of malignant cells all showing strong expression of A2AR in all tumor cells. (H-score, in this case, was 300). 


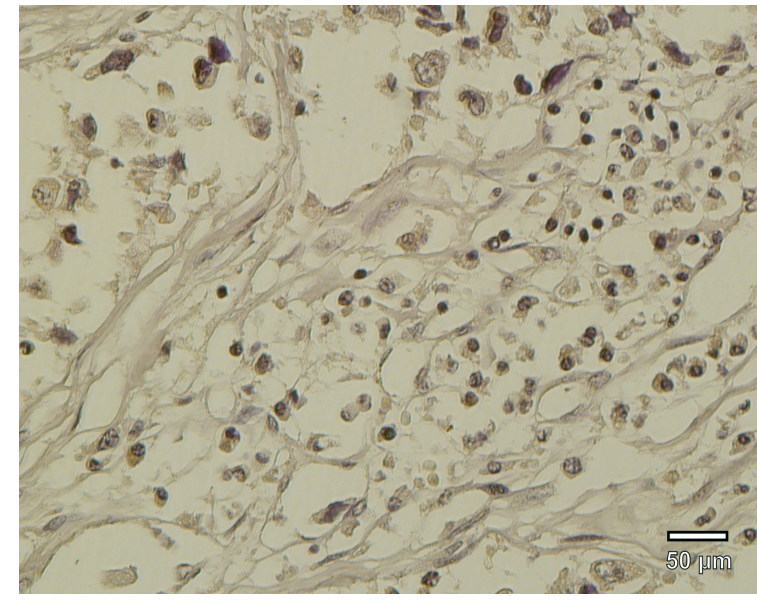

Figure 3. Microscopic picture showing $A 2 A$ receptor expression on the tumor-infiltrating lymphocytes (TILs) in breast cancer.
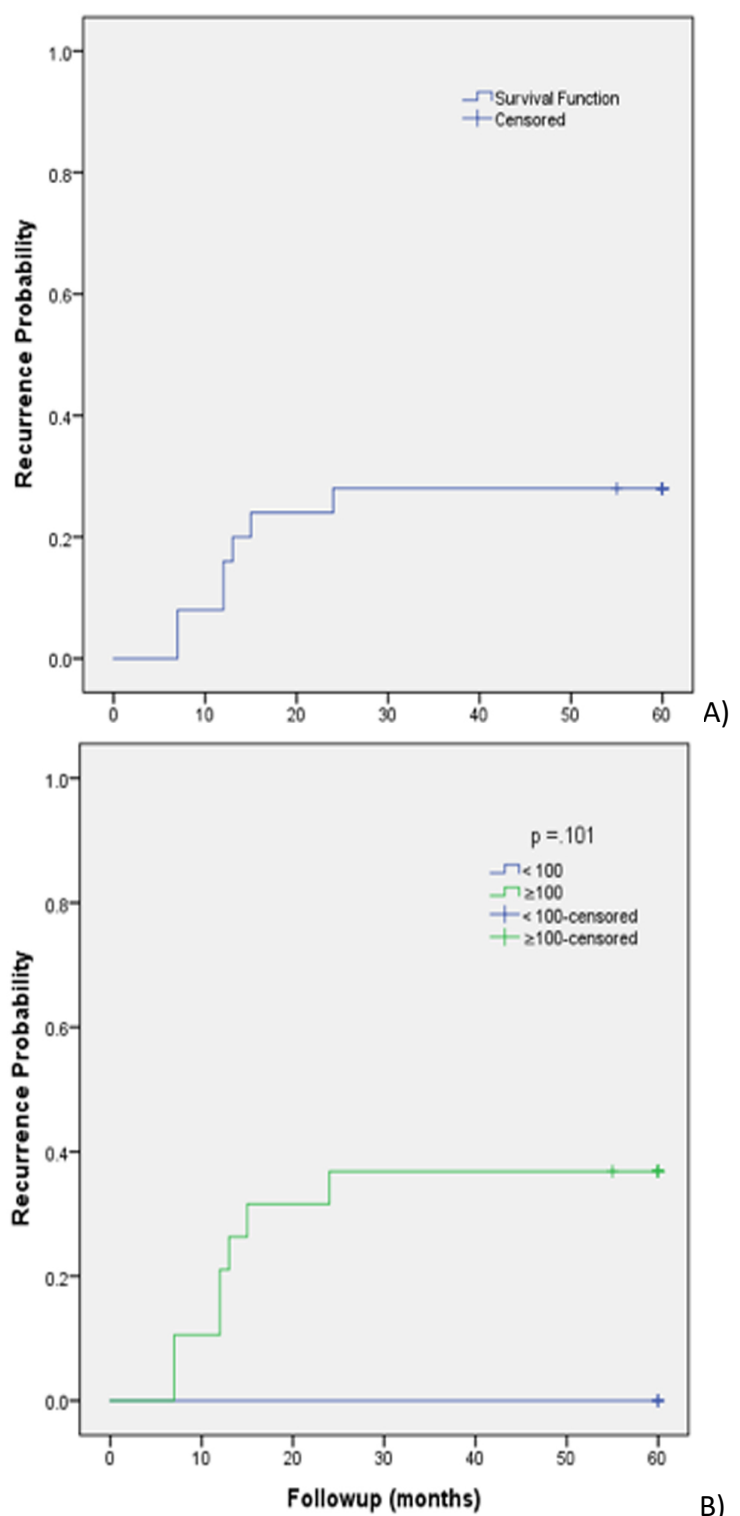

Figure 4. Kaplan-Meier estimates for the entire cohort of (A) Overall recurrence, and (B) Recurrence stratified by A2A H-score.
A2ARs were also strongly expressed in most tumors showing Progesterone receptor expression and those with HER2 overexpression. ( $p=0.031$ Chi-square test).

No statistically significant association was found between A2AR expression and Tumor size, lymph node status, tumor type, tumor grade, lymphovascular invasion, the presence of an insitu component or the percentage of tumorinfiltrating lymphocytes (TILs). (Table 1).

Kaplan-Meier estimates for overall recurrence was $27 \%$ at 5 years. Overall recurrence for patients who had a strong expression $(\geq 100)$ was approximately $37 \%$ at 5 years. Those who had weak expression $(<100)$ overall recurrence was about $0 \%$, yet there was no statistically significant difference noted, $p=0.101$ (figure 4 $a, b)$. Therefore, the expression of A2AR did not show any statistically significant association with recurrence, metastasis or patient survival when these patients were followed up for a period between 2 and 5 years after treatment.

\section{DISCUSSION}

The treatment of breast cancer has achieved great success in the past decade leading to a dramatic improvement in patient overall survival (Miller et al., 2016; Siegel et al., 2016). Nevertheless, there is still a continuous search for novel therapeutic targets that would offer these patients a better outcome and an improved quality of life.

In recent years, the use of immune checkpoint inhibitors has emerged as a highly promising treatment modality in various types of cancers. PD-L1 monoclonal antibodies are currently used in addition to chemotherapy for the treatment of advanced malignant melanoma (Johnson et al., 2015).

However, the role of these immunotherapy molecules in the treatment of breast cancer is still being investigated. In our study, we investigated the expression of another immune checkpoint molecule, Adenosine receptors (A2AR) in different molecular subtypes of breast cancer. To the best of our knowledge, this is the first study to investigate the clinicopathological implications of A2ARs expression in breast cancer. 
Ohta and Sitkovsky showed for the first time in 2001 that A2A receptor-deficient mice were unable to control inflammation resulting in an exaggerated immune response and extensive tissue disruption and cell death (Ohta \& Sitkovsky, 2001). Since that time, the Adenosine receptor pathway has emerged as a crucial "immune checkpoint" and in-vitro studies have successively proved that stimulation of A2A receptors on immune cells like T-cells, NK-cells and dendritic cells inhibited the activity of these cells thus creating an immunosuppressed niche that is capable of evading the body's immune response (Morello et al., 2009).

In our study, we confirmed for the first time that A2A receptors were expressed not only on tumor immune cells but also highly expressed in the breast cancer tumor cells themselves. We demonstrated that their expression was significantly higher in young aged patients $1<50$ years) compared to older ones (older than 50 years of age) and also was associated with a high mitotic score and a higher proliferative index in the studied cases. This finding suggests a possible role for these receptors in enhancing tumor cell proliferation and promoting more aggressive behavior.

The present study has also demonstrated that A2ARs are more likely to be show strong expression in the more aggressive molecular subtypes of breast cancer (Luminal B, HER-2 enriched and TNBC) compared to the more indolent luminal A breast cancers. These tumors subtypes are also known to show less response to current treatment modalities. It has been previously suggested that younger women were more likely to present with the more aggressive tumor subtypes like TNBC compared to older females, aged 60 years and above, who most likely present with luminal $A$ subtype rather than with TNBC which is known to be the least common in this age group (McGuire et al., 2015)

Our findings, as well as those previous ones, has lead us to speculate that the expression of A2AR on tumor cells could be an important factor leading to enhanced tumor cell proliferation and thereby a more aggressive tumor phenotype.
It is well documented that A2AR stimulation on immune cells has an immunosuppressive effect (Allard et al., 2016; Antonioli et al., 2013; Longhi et al., 2013). However, very few studies have investigated the effect of A2AR stimulation on the tumor cells themselves.

One in-vitro study has suggested that adenosine receptor expression on the tumor cells may directly enhance tumor cell growth (Bavaresco et al., 2008). Another similar study investigated the effect of adenosine on in-vitro cultured tumor cells and showed that the addition of adenosine enhanced cell growth whereas cotreatment with A2AR antagonists had an opposite effect thus proving that this growthpromoting effect is mediated via $\mathrm{A} 2 \mathrm{~A}$ receptors (Bavaresco et al., 2008). Another study has also shown that A2AR stimulation by adenosine antagonists was associated with increased tumor cell apoptosis (Mediavilla-Varela et al., 2013). Furthermore, it was found that inhibition of the enzymatic activity of CD73, on the tumor cells, resulted in a reduction of adenosine level with inhibition of tumor cell proliferation and enhanced apoptosis (Zhi et al., 2010).

A2ARs were also found to be expressed in the tumor cells in different other tumors; such as neuroblastoma, monocytic lymphoma, T-cell leukemia, melanoma, epidermoid cells, colon carcinoma, and human breast cancer MCF-7 cells (Gessi et al., 2011). However, the exact effect of $A 2 A$ receptor stimulation was found to be different from one tumor type to the other. For instance, in human A375 melanoma cells and Caco-2 human colonic cancer cells, A2Areceptors activation was associated with a caspase- 9 and caspase- 3 mediated apoptotic cell death following mitochondrial damage (Merighi et al., 2002; Yasuda et al., 2009). Whereas, stimulating $\mathrm{A} 2 \mathrm{~A}$ receptors by agonists stimulated the proliferation of MCF-7 cells (Etique et al., 2009). Nevertheless, there is still not enough research studying the in-vivo effect of $A 2 A$ receptors in breast cancer within the

tissue microenvironment and the exact mechanisms downstream these receptors in breast cancer cells has not yet been fully established (Gessi et al., 2011). An in vivo study on CD73-knockout mice studying B16F10 melanoma has suggested a possible role for 
Table 1. Association of A2AR expression with clinicopathological features of the tumors

\begin{tabular}{|c|c|c|c|c|}
\hline & \multicolumn{3}{|c|}{ No (\%) } & \multirow[t]{2}{*}{$p$-value } \\
\hline & $\begin{array}{c}\text { A2A Receptor } \\
\text { Expression } \\
(\mathrm{H}-\mathrm{score}<100)(8)\end{array}$ & $\begin{array}{c}\text { A2A Receptor } \\
\text { Expression } \\
\text { (H-score } \geq 100 \text { ) } \\
(22)\end{array}$ & Total (\%) & \\
\hline Age group (years) $n=30$ & & & & $p=0.018^{*}$ \\
\hline$\leq 50 y$ & $2(11.11 \%)$ & $16(88.88 \%)$ & $18(60 \%)$ & \\
\hline$>50 y$ & $6(50 \%)$ & $6(50 \%)$ & $12(40 \%)$ & \\
\hline Tumor size $n=30$ & & & & $p=0.361$ \\
\hline $\mathrm{T} 1 / \mathrm{T} 2$ & $4(21.05 \%)$ & 15 (78.94\%) & $19(63.33 \%)$ & \\
\hline $\mathrm{T} 3 / \mathrm{T} 4$ & $4(36.36 \%)$ & $7(63.63 \%)$ & $11(36.66 \%)$ & \\
\hline Lymph node status $n=29$ & & & & $p=0.495$ \\
\hline Negative (NO) & $2(40 \%)$ & $3(60 \%)$ & $5(16.66 \%)$ & \\
\hline Positive (N1/N2/N3) & $6(25 \%)$ & $18(75 \%)$ & $24(83.33 \%)$ & \\
\hline Tumor Grade $n=30$ & & & & $p=0.783$ \\
\hline G1 & $1(33.33 \%)$ & $2(66.66 \%)$ & $3(10 \%)$ & \\
\hline $\mathrm{G} 2 / 3$ & $7(25.92 \%)$ & $20(74.07 \%)$ & $27(90 \%)$ & \\
\hline Mitotic score $n=30$ & & & & $p=0.013^{*}$ \\
\hline 1 & $6(46.15 \%)$ & $7(53.84)$ & $13(43.33 \%)$ & \\
\hline 2 & $1(6.25 \%)$ & $15(93.75 \%)$ & $16(53.33 \%)$ & \\
\hline 3 & $1(100 \%)$ & $0(0.00 \%)$ & $1(3.33 \%)$ & \\
\hline ER expression $n=30$ & & & & $p=0.098$ \\
\hline Positive & 7 (36.84\%) & $12(63.15 \%)$ & $19(63.3 \%)$ & \\
\hline Negative & $1(9.09 \%)$ & $10(90.90 \%)$ & $11(36.6 \%)$ & \\
\hline PR expression $n=30$ & & & & $p=0.031^{*}$ \\
\hline Positive & $8(38.09 \%)$ & $13(61.90 \%)$ & $21(70 \%)$ & \\
\hline Negative & $0(0.00 \%)$ & $9(100 \%)$ & $9(30 \%)$ & \\
\hline Her-2 expression $n=30$ & & & & $P=0.031^{*}$ \\
\hline Positive & $0(0.00 \%)$ & 9 (100\%) & $9(30 \%)$ & \\
\hline Negative & $8(38.09 \%)$ & $13(61.90 \%)$ & $21(70 \%)$ & \\
\hline Ki-67\% n=30 & & 31 & & $p=0.018^{*}$ \\
\hline$\leq 20 \%$ & $6(50 \%)$ & $6(50 \%)$ & $12(40 \%)$ & \\
\hline$>20 \%$ & $2(11.11 \%)$ & $16(88.88 \%)$ & $18(60 \%)$ & \\
\hline Histological type $n=30$ & & & & $p=0.377$ \\
\hline IDC, NST & $8(28.75 \%)$ & $20(71.42 \%)$ & $28(93.33 \%)$ & \\
\hline ILC & $0(0.00 \%)$ & $2(100 \%)$ & $2(6.66 \%)$ & \\
\hline Molecular subtype $n=30$ & & & & $p=0.028^{*}$ \\
\hline Luminal A & $6(60 \%)$ & $4(40 \%)$ & $10(33.33 \%)$ & \\
\hline Luminal B & $2(15.38 \%)$ & $11(84.61 \%)$ & $13(43.33 \%)$ & \\
\hline Her-2 enriched & $0(0.00 \%)$ & $1(100 \%)$ & $1(3.33 \%)$ & \\
\hline TNBC & $0(0.00 \%)$ & $6(100 \%)$ & $6(20 \%)$ & \\
\hline Basal-like & $0(0.00 \%)$ & $0(0.00 \%)$ & $0(0.00 \%)$ & \\
\hline $\begin{array}{l}\text { Intra-tumoral Lymphocytes } \\
\text { (ITLs) } n=30\end{array}$ & & & & $p=0.536$ \\
\hline $0 / 1$ & $7(29.16 \%)$ & $17(70.83 \%)$ & $24(80 \%)$ & \\
\hline $2 / 3$ & $1(16.66 \%)$ & $5(83.33 \%)$ & $6(20 \%)$ & \\
\hline Outcome $n=30$ & & & & $p=0.222$ \\
\hline No Recurrence/metastasis & $6(35.29 \%)$ & $11(64.70 \%)$ & $17(56.66 \%)$ & \\
\hline Recurrence /metastasis & $2(15.38 \%)$ & $11(84.61 \%)$ & $13(43.3 \%)$ & \\
\hline
\end{tabular}

adenosine through its various receptors in controlling tumor vascularization with a possible mitogenic effect on endothelial cells (Koszałka et al., 2016). Thus, adding to the multifaceted role of adenosine and its receptors in controlling tumor growth.
Among our studied cases, only two of the patients who showed low A2AR expression developed recurrences/metastasis during the follow-up period, yet this did not prove to be statistically significant nor did the expression of A2ARs show any significant association with overall survival in our patients. 
In contrast to our findings, a study on non-small cell lung cancer (NSCLC) showed that A2ARs was highly expressed in $49.2 \%$ of the cases and their expression was associated with a significantly better overall survival that is recurrence-free in patients with high A2AR expression compared to those with low A2AR expression (Inoue et al., 2017). This, in turn, supports the notion that the role of these receptors may differ from one tumor to another. Therefore, more studies are still needed to further elucidate their effect invivo. Whereas the use of A2AR antagonists in Lung adenocarcinoma induced apoptotic cell death (Mediavilla-Varela et al., 2013), their effect on breast cancer cells has not been fully investigated. Therefore, it is highly recommended that A2AR antagonists be further tested on different breast cancer cell lines invitro as well as in -vivo models to further demonstrate their effect on tumor cell survival, proliferation, and migration.

Moreover, studies are also still needed to determine the relevant downstream signaling pathways through which A2A receptors exert their effect on tumor cells not only immune cells. Understanding the signaling pathways involved could guide more rational combinations of chemotherapeutic agents with A2AR antagonism to improve the therapeutic outcome.

\section{CONFLICT OF INTEREST}

All authors declared no conflicts of interest.

\section{FUNDING}

This work was partly funded by Boehringer Ingelheim pharmaceutical company, United Arab Emirates.

\section{REFERENCES}

Allard B., Beavis P.A., Darcy P.K., \& Stagg J., (2016). Immunosuppressive activities of adenosine in cancer. Current opinion in pharmacology, 29: 716.

Allard D, Allard B, Gaudreau PO, Chrobak P, \& Stagg J (2016). CD73-adenosine: a next-generation target in immuno-oncology. Immunotherapy, 8(2): 145-163.

Antonioli L, Blandizzi C, Pacher P, \& Haskó G (2013). Immunity, inflammation and cancer: a leading role for adenosine. Nature Reviews Cancer, 13(12): 842-857.

Antonioli L, Yegutkin G G, Pacher P, Blandizzi C, \& Haskó G (2016). Anti-CD73 in cancer immunotherapy: awakening new opportunities. Trends in cancer, 2(2): 95-109.

Bavaresco L, Bernardi A, Braganhol E, Cappellari A R, Rockenbach L, Farias P F, Battastini AMO (2008). The role of ecto-5'-nucleotidase/CD73 in glioma cell line proliferation. Molecular and cellular biochemistry, 319(1-2): 61-68.

Beavis PA, Milenkovski N, Henderson MA, John LB, Allard B, Loi S, Darcy PK (2015). Adenosine receptor $2 A$ blockade increases the efficacy of anti-PD-1 through enhanced antitumor T-cell responses. Cancer immunology research, 3(5): 506-517.

Bustreo S, Osella-Abate S, Cassoni P, Donadio M, Airoldi M, Pedani F, Castellano I (2016). Optimal Ki67 cut-off for luminal breast cancer prognostic evaluation: a large case series study with a long-term follow-up. Breast cancer research and treatment, 157(2): 363-371.

Eltzschig HK (2013). Extracellular adenosine signaling in molecular medicine. In: Springer.

Etique N, Grillier-Vuissoz I, Lecomte J, \& Flament S (2009). Crosstalk between adenosine receptor (A2A isoform) and ERa mediates ethanol action in MCF-7 breast cancer cells. Oncology reports, 21(4): 977-981.

Fredholm BB, IJzerman AP, Jacobson, KA, Klotz KN, \& Linden J (2001). International Union of Pharmacology. XXV. Nomenclature and classification of adenosine receptors. Pharmacological reviews, 53(4): 527-552.

Gessi S, Merighi S, Sacchetto V, Simioni C, \& Borea P $A$ (2011). Adenosine receptors and cancer. Biochimica et Biophysica Acta (BBA)Biomembranes, 1808(5): 1400-1412.

Hatfield SM, \& Sitkovsky M (2016). A2A adenosine receptor antagonists to weaken the hypoxiaHIF-1 $\alpha$ driven immunosuppression and improve immunotherapies of cancer. Current opinion in pharmacology, 29: 90-96.

Häusler SF, del Barrio IM, Diessner J, Stein RG, Strohschein J, Hönig A, Wischhusen J (2014). Anti-CD39 and anti-CD73 antibodies A1 and 7G2 improve targeted therapy in ovarian cancer by blocking adenosine-dependent immune evasion. American journal of translational research, 6(2): 129.

Inoue $\mathrm{Y}$, Yoshimura K, Kurabe N, Kahyo T, Kawase A, Tanahashi M, Shinmura K (2017). Prognostic impact of CD73 and A2A adenosine receptor expression in non-small-cell lung cancer. Oncotarget, 8(5): 8738.

Inwald $E$, Klinkhammer-Schalke $M$, Hofstädter $F$, Zeman $F$, Koller $M$, Gerstenhauer $M$, \& Ortmann O (2013). Ki-67 is a prognostic parameter in breast cancer patients: results of a large population-based cohort of a cancer 
registry. Breast cancer research and treatment, 139(2): 539-552.

Johnson DB, Peng C, \& Sosman JA (2015). Nivolumab in melanoma: latest evidence and clinical potential. Therapeutic advances in medical oncology, 7(2): 97-106.

Koszałka P, Gołuńska M, Urban A, Stasiłojć G, Stanisławowski M, Majewski M, Bigda J (2016). Specific activation of $A 3, A 2 A$ and $A 1$ adenosine receptors in CD73-knockout mice affects B16F10 melanoma growth, neovascularization, angiogenesis and macrophage infiltration. PloS one, 11(3): e0151420.

Lee HJ, Kim JY, Park IA, Song IH, Yu JH, Ahn JH, \& Gong $G$ (2015). Prognostic significance of tumor-infiltrating lymphocytes and the tertiary lymphoid structures in HER2-positive breast cancer treated with adjuvant trastuzumab. American journal of clinical pathology, 144(2): 278-288.

Leone RD, Lo YC, \& Powell JD (2015). A2aR antagonists: Next generation checkpoint blockade for cancer immunotherapy. Computational and structural biotechnology journal, 13: 265-272.

Longhi MS, Robson SC, Bernstein SH, Serra S, \& Deaglio $S$ (2013). Biological functions of ectoenzymes in regulating extracellular adenosine levels in neoplastic and inflammatory disease states. Journal of molecular medicine, 91(2): 165-172.

McGuire A, Brown J A, Malone C, McLaughlin R, \& Kerin MJ (2015). Effects of age on the detection and management of breast cancer. Cancers, 7(2): 908-929.

Mediavilla-Varela M, Luddy K, Noyes D, Khalil FK, Neuger AM, Soliman H, \& Antonia SJ (2013). Antagonism of adenosine A2A receptor expressed by lung adenocarcinoma tumor cells and cancer associated fibroblasts inhibits their growth. Cancer biology \& therapy, 14(9): 860868.

Merighi S, Mirandola P, Milani D, Varani K, Gessi S, Klotz KN, Borea PA (2002). Adenosine receptors as mediators of both cell proliferation and cell death of cultured human melanoma cells. Journal of Investigative Dermatology, 119(4): 923-933.

Miller KD, Siegel RL, Lin CC, Mariotto AB, Kramer JL, Rowland JH, Jemal A (2016). Cancer treatment and survivorship statistics, 2016. CA: a cancer journal for clinicians, 66(4): 271-289.
Morello S, Sorrentino R, \& Pinto A (2009). Adenosine A2a receptor agonists as regulators of inflammation: pharmacology and therapeutic opportunities. J Receptor Ligand Channel Res, 2, 11-17.

Ohta A (2016). A metabolic immune checkpoint: adenosine in tumor microenvironment. Frontiers in immunology, 7.

Ohta A \& Sitkovsky M (2001). Role of G-proteincoupled adenosine receptors in downregulation of inflammation and protection from tissue damage. Nature, 414(6866): 916-920.

Pirker R, Pereira JR, von Pawel J, Krzakowski M, Ramlau R, Park K, Störkel S (2012). EGFR expression as a predictor of survival for firstline chemotherapy plus cetuximab in patients with advanced non-small-cell lung cancer: analysis of data from the phase 3 FLEX study. The lancet oncology, 13(1): 33-42.

Salgado R, Denkert C, Demaria S, Sirtaine N, Klauschen F, Pruneri G, Penault-Llorca F (2014). The evaluation of tumor-infiltrating lymphocytes (TILs) in breast cancer: recommendations by an International TILS Working Group 2014. Annals of oncology, 26(2): 259-271.

Sheth S, Brito R, Mukherjea D, Rybak LP, \& Ramkumar V (2014). Adenosine receptors: expression, function and regulation. International journal of molecular sciences, 15(2): 2024-2052.

Siegel RL, Miller KD, \& Jemal A (2016). Cancer statistics, 2016. CA: a cancer journal for clinicians, 66(1): 7-30.

Tarver T (2012). Cancer Facts \& Figures 2012. American Cancer Society (ACS) Atlanta, GA: American Cancer Society, 2012. 66 p., pdf. Available from. In: Taylor \& Francis.

Yasuda $Y$, Saito $M$, Yamamura $T$, Yaguchi $T$, \& Nishizaki T (2009). Extracellular adenosine induces apoptosis in Caco-2 human colonic cancer cells by activating caspase- $9 /-3$ via A 2 a adenosine receptors. Journal of gastroenterology, 44(1): 56-65.

Zhi X, Wang Y, Zhou X, Yu J, Jian R, Tang S, Zhou P (2010). RNAi-mediated CD73 suppression induces apoptosis and cell-cycle arrest in human breast cancer cells. Cancer science, 101(12): 2561-2569. 


\section{Egyptian Association for Cancer Research (EACR)}

http://eacr.tanta.edu.eg/

EACR is an NGO society that was declared by the Ministry of Social Solidarity (Egypt) No. 1938 in 19/11/2014 based on the initiative of Prof. Mohamed Labib Salem, the current Chairman of EACR. EACR aims primarily to assist researchers, in particular young researchers in the field of cancer research through workshops, seminars and conferences. Its first international annual conference entitled "Anti-Cancer Drug Discovery" was successfully organized in April 2019 (http://acdd.tanta.edu.eg). Additionally, EACR aims to raise the awareness of the society about the importance of scientific research in the field of cancer research in prediction, early diagnosis and treatment of cancer. EACR is also keen to outreach the scientific community with periodicals and news on cancer research including peer-reviewed scientific journals for the publication of cutting-edge research. The official scientific journal of EACR is "International Journal of Cancer and biomedical Research (IJCBR: https://jcbr.journals.ekb.eg) was successfully issued in 2017 and has been sponsored by the Egyptian Knowledge Bank (EKB: www.ekb.eg).

\section{EACR Chairman,}

Prof. Mohamed Labib Salem, PhD

Professor of Immunology

Faculty of Science, Tanta Universiy, Egypt 


\section{GUIDE FOR AUTHORS}

Publisher :The International Journal of Cancer and Biomedical Research (IJCBR) is an International and interdisciplinary journal of preclinical and clinical studies in the area of cancer and biomedical research. It is a peer-reviewed journal in English, published quarterly (in March, June, September, and December) by the Egyptian Association for Cancer Research (EACR) in both print and online formats (4 issues making a volume). Special issues or supplements may also be produced from time to time upon agreement with the Editorial Board.

Scope :The main aim of IJCBR is to attract the best research in animal and human biology in health and diseases from across the spectrum of the biomedical sciences at the molecular, cellular, organ, and whole animal levels especially those that are related to cancer research, including causes, prediction, diagnosis, prognosis, and therapy.

Publication Fees :The journal does charge for submission, processing, or publication of manuscripts (2000 LE for Egyptians or $250 \$$ for non-Egyptians; EACR members receive 15\% discount on publication). Of them Peer-review fees (300 LE) should be paid on submission (non-refundable). For the fast-track production of the accepted manuscript, another 500 LE is paid.

General specifications for different types of article

- Submitted manuscripts should not have been published previously, except in a limited form (e.g. short communication to a symposium or as part of MSc or PhD theses) and should not be under consideration for publication by other journals.

- All co-authors should agree with the content of the manuscript. Authors must have obtained permission to use any copyrighted material in the manuscript before submission.

IJCBR publishes different types of articles

- Original Article (6000 words with $\mathbf{4}$ tables and $\mathbf{4}$ figures, maximum $\mathbf{8}$ display items): Articles with novel findings are the target of IJCBR. Articles presenting a detailed description of a new technique, comparison of existing methods, meta-analyses with comprehensive and in-depth discussion are considered. Papers in a numbered series are not accepted unless all are submitted at the same time.

- Short communications or case study (3000 words with $\mathbf{4}$ display items): Short communications present exceptionally exciting, novel or timely contents are considered. They will be peer-reviewed in the same way as research papers. The references are restricted to 15 .

- Reviews or systematic review (9000 words with $\mathbf{1 0}$ display items): They are invited by the Editorial Board or unsolicited. Review articles have to be contemporary and comprehensive and add information to the knowledge. Sharp critical analyses of novel data or concepts are encouraged. When relevant, a statistical analysis of data and a meta-analysis approach are recommended.

- Opinion papers, letter to the editor or comment to the editor (1500 words with $\mathbf{2}$ display items): They are submitted by invitation of the Editorial Board. They are short papers, which aim to inform scientists, industry, and the public and policymakers about cutting-edge issues in research or the impact of research. They reflect the opinion of their authors who bear full responsibility of the published paper. The references are restricted to 10 .

- Conference/Symposium papers: The journal will consider for publication the results of original work and critical reviews that are presented at conferences/symposia. Symposium organizers who wish to publish bundles of papers from a symposium/conference in IJCBR should first contact the Editor-in-Chief of the IJCBR (EACR@unv.tanta.edu.eg) for agreement. Supplementary material can be proposed and will be made available online. The responsibility for the preparation of a paper in a form suitable for publication lies with the author.

- Thesis: IJCBR can publish the summary and abstract of Master and PhD theses in a special issue.

English: Good quality of written English is required. Spelling may be in British or American English but must be consistent throughout the paper. Care should be exercised in the use of biological terminology that is ill-defined or of local familiarity only. We recommend that authors have their manuscripts checked by an English language native speaker before submission.

Manuscript layout: Manuscripts should be prepared using a standard word processing program and presented in a clear readable format with easily identified sections and headings. The manuscript layout is based on the following directions.

- The main text contains Title, Abstract, Keywords, Introduction, Material and Methods, Results, Discussion, References, Tables, figures.

- The title needs to be concise and informative. Use bold, with an initial capital for the first word only and for words that ordinarily take capitals.

- Short (running) title (max 80 characters including spacing).

- The article text should be typed with double line spacing with wide margins $(2.5 \mathrm{~cm})$.

- The lines must be continuously numbered; the pages must also be numbered.

- Font Calibri 12 should be used for the text, and 12 for the tables, figure legends and references.

- The sections should typically be assembled in the following order:

- Title page contains title, authors' names, full affiliations, acknowledgements and the corresponding author's contacts and Short title.

Abstract (max 250 words, single paragraph): The abstract should be complete and understandable without citation, references, table, or figure. Use structured abstract: Background, Aim, Materials \& Methods, Results and Conclusion. The context and the rationale of the study are presented succinctly to support the objectives. The experimental methods and main results are summarized but should not be overburdened by numerical values or probability values. The abstract ends with a short and clear conclusion. 
Keywords: Up to five short and specific keywords should complement the title with respect to indicating the subject of the paper in alphabetic order.

Introduction: The introduction briefly outlines the context of the work, presents the current issues that the authors are addressing and the rationale to support the objectives, and clearly defines the objectives.

Material and methods: Material and methods should be described in sufficient details so that others can repeat the experiment. Reference to previously published work may be used to give methodological details, provided that said publications are readily accessible and in English. The code of ethics should be followed for all experiments use animals or human samples.

Statistical analysis of results: The statistical design and the models of statistical analysis must be described, as well as each of the statistical methods used. Sufficient statistical details must be given to allow replication of the statistical analysis. The experimental unit should be defined (e.g., individual or group of animals).

Results: Data are presented as tables and figures. Brief description of the results for each table and figure should be presented. Unpublished data can be mentioned when necessary.

Discussion: Should be separate from the Results section and should focus only on intra- and inter-data discussion (the data in the results section) as well as with the relative data in the literature. Don't repeat information already presented in the Introduction section. Start the first paragraph in the Discussion with a paragraph stating the rationale behind the study, the objectives, and the main findings. End Discussion with a short conclusion.

Acknowledgements: In this section, the authors may acknowledge (briefly) their support staff.

Conflict of interest: All papers with a potential conflict of interest must include a description/explanation in a separate heading.

Funding details: The authors should state the source of findings of the study (with research funder and/or grant number). If no fund, the authors should state that the study is self-funded.

\section{References}

Citation of references: In the text, references should be cited by the author(s) surname(s) and the year of publication (e.g. Salem, 2020). References with two authors should be cited with both surnames (e.g. Salem and Meshrif, 2021). References with three or more authors should be cited with the first author followed by et al. (in italics; e.g. Salem et al., 2021). Names of organizations used as authors (e.g. Food and Drug Administration) should be written out in full in the list of references and on the first mention in the text. Subsequent mentions may be abbreviated (e.g. FDA).

- List of references. Literature cited should be listed in alphabetical order by authors' names. It is the author's responsibility to ensure that all references are correct. All authors should be written and so the full journal name.

- $\quad$ References from journal articles are formatted in APA as this example: Al-Amoudi WM (2018). Toxic effects of Lambdacyhalothrin on the rat thyroid. Involvement of oxidative stress and ameliorative effect of ginger extract. Toxicology Reports, 5: 728-736.

- $\quad$ References from books or official reports are formatted as this example. Kebreab E, Dijkstra ANM, Bannink A, Gerrits WJJ, \& France J (2006). Nutrient digestion and utilization in farm animals. CABI Publishing. Wallingford, UK.

- References from chapters or parts of books are formatted as this example. Nozière $P, \&$ Hoch $T$ (2006). Modelling fluxes of volatile fatty acids from rumen to portal blood. In: Nutrient digestion and utilization in farm animals (Kebreab E, Dijkstra ANM, Bannink A, Gerrits WJJ \& France J, eds.), pp. 40-47. CABI Publishing. Wallingford, UK.

Tables: The data should be presented in tables or in graphs, not both.

- Each table should be placed on a separate page at the end of the main text.

- Tables are numbered consecutively using Arabic numbering. They are referred to as Table 1 , Table 2, etc., with capital ' $T$ ', no italics

- $\quad$ Each table has its explanatory caption. The caption is sufficient to permit the table to be understood without reference to the text.

- Abbreviations used in tables/figures have to be defined either as footnotes or in the caption.

\section{Figures}

- $\quad$ Package the figures in a single PowerPoint file. Each figure in a separate slide.

- Figure size should be readable in a width of approximately 8-175 $\mathrm{mm}$ (i.e. the maximum size of printing over two columns).

- Ensure that the font size is large enough to be readable at the final print size, use Calibri font to ensure that they are consistent throughout the figures.

- $\quad$ The figures should preferably be provided as TIFF or EPS files.

- The resolutions of figures must be at least $300 \mathrm{dpi}$.

- Preparation of images for a manuscript: For guidance, we refer to the Journal of Cell Biology's instructions to authors (http://jcb.rupress.org/site/misc/ifora.xhtml\#image_aquisition).

- If a cropped image is included in the main text of a paper (e.g. a few lanes of a gel), display the full original image, including the appropriate controls, the molecular size ladder and/or the scale as relevant, as a single figure in a Supplementary Material file to facilitate peer-review and for subsequent online publication.

- Supplementary material is submitted along with the main manuscript in a separate file and identified at uploading as "Supplementary File - for Online Publication Only" The title of the article is included at the top of the supplementary material.

Corresponding author's guidelines: Upon acceptance the corresponding author is required to send his/her recent formal photo to be attached to the front page of the article. 


\title{
International Journal of Cancer \& Biomedical Research
}

(IJCBR) Online ISSN 2682-2628

\author{
Editor-in-Chief \\ Mohamed Labib Salem, PhD \\ Tanta University, Egypt
}

\begin{tabular}{l} 
EACR Board \\
\hline Nehal Elmashad, MD \\
Tanta University, Egypt \\
Nabil Mohy Eldin, PhD \\
Kafrelsheikh University, Egypt \\
Doaa Al-Ghareeb, PhD \\
Alexandria University, Egypt \\
Abdel-Aziz Zidan, PhD \\
Damanhour University, Egypt
\end{tabular}

\begin{tabular}{l} 
Managing Editor \\
\hline Wesam Meshrif, PhD \\
Tanta University, Egypt \\
Sohaila Galal, PhD \\
Tanta University, Egypt \\
Production and Contact \\
\hline Hamdi Kandil \\
Tanta University, Egypt \\
Email: ljcbr100@gmail.com
\end{tabular}

\section{Advisory Board}

Alberto Montero, MD

Taussig Cancer Center, Cleveland,

USA

Yi Zhang, MD

Zhengzhou University, China

Mark Robunstein, Ph D

Medical University of South

Carolina, USA

Mohsen Farid, Ph D

Derby University, USA

Natarajan Muthusamy, Ph D

Ohio State University, USA

Hideki Kasuya, MD

Nagoya University, Japan

Sherif El-Khamisy, Ph D

Sheffield University, UK

Mohamed Ghanem, Ph D

Kafr Elshikh University, Egypt

Sayed Bakry, Ph D

Alazhar University, Egypt

Sameh Ali, Ph D

Nationa Liver Institute, Egypt

Gamal Badr, Ph D

Assuit University, Egypt

Nadia Hamdy, Pharm D

Ain Shams University, Egypt

\section{Editorial Board}

\section{Clinical studies}

Hesham Tawfik, MD

Tanta University, Egypt

Mohamed Attia, MD

Tanta University, Egypt

Mohamed Elshanshory, MD

Tanta University, Egypt

Essam Elshiekh, MD

Tanta Cancer Center, Egypt

Rasha Eraky, MD

Tanta University, Egypt

Shaima Abou-Kjatwa, MD

Tanta University, Egypt

Marcela Diaz, MD

Cleveland Clinic Foundation, USA

Mohamed Abou-El-Enein, MD

Charité Universitätsmedizin Berlin,

Germany
Alaa Eldin Almostafa, MD

McGill University, Canada

Olfat Gadallah, MD

Tanta University, Egypt

Nagla Sarhan, MD

Tanta University, Egypt

Naglaa Fathy, Pharm D

Zagazik University, Egypt

Mohamed Salama, MD

Mansoura University, Egypt

Mona Marie, MD

Alexandria University, Egypt

Preclinical studies

Mostafa El-Sheekh

Tanta University, Egypt

El-Refai Kenawy, Ph D

Tanta University, Egypt

Mohamed Noureldin, Ph D

Banaha University, Egypt

Yousry Albolkiny, Ph D

Tanta University, Egypt

Elsayed Salim, Ph D

Tanta University, Egypt

Shengdian Wang, Ph D

Chinese Academy of Sciences,

China

Sabry El Naggar, Ph D

Tnata Univesity, Egypr

Faris Alenzi, Ph D

Prince Sattam bin Abdulaziz

University, KSA

Ibrahim El-Sayed, Ph D

Menoufia University, Egypt

Tarek Aboul-Fadl, Ph D

Assiut University, Egypt

Rabab Khairat, Ph D

National Research Center,

Giza, Egypt

Wael Lotfy, Ph D

Alexandria University, Egypt

Ashraf Tabll, Ph D

National Research Center, Egypt

Nahla Shoukry, Ph D

Suez University, Egypt
Medhat Eldenary, Ph D

Tanta University, Egypt

Azza Hasan, Ph D

Menufia University, Egypt

Nanees Gamal Eldin, Ph D

Tanta University, Egypt

Mohamed Mansour, UK

Sabbah Hammoury, Ph D

Alexandria Ayadi Almostaqba

Oncology Hospital, Egypt

Nehal Aboulfotoh, Ph D

Zewail City for Science and

Technology, Cairo, Egypt

Amir Elkhami, Ph D

Galaxo, San Francisco, USA

Ahmed Alzohairy, Ph D

Zagazi University, Egypt

Wgady Khalil, Ph D

National Research Center, Egypt

Amr Amin, Ph D

United Arab Emirates

University, UAE

AbdelRahman Zekri, Ph D

National Cancer Institute, Egypt

Hussein Khamis, Ph D

Alexandria University, Egypt

Magdy Mahfouz, Ph D

Kafr Elsheikh University, Egypt

Ehab Elbedewey, Ph D

Tanta University, Egypt

Abeer Badr, Ph D

Cairo University, Egypt

Mamdooh Ghoneum, Ph D

Charles Drew University of

Medicine \& Science, USA

Haiam Abou Elela, Ph D

National Institute of Oceanography and Fisherie, Egypt

Maha EL-Demellawi, Ph D City for Scientific Research \&

Technology Applications, Egypt

Desouky Abd-El-Haleem, Ph D

City for Scientific Research \&

Technology Applications, Egypt 